drug retention at a time when her dietary intake was below the level of $400 \mu \mathrm{g}$ folic acid-the level shown by Kahn to be necessary to counteract co-trimoxazole antagonism of folic acid.

In addition to these factors, however, it may be expected that her folic acid consumption was much higher than normal as she had evidence of a significant haemolytic anaemia. It is well known that a haemolytic anaemia may cause megaloblastic anaemia due to depletion of body folic acid storesChanarin, Dacie \& Mollin (1959). On the other hand, Clarkson et al. (1970) did not comment on megaloblastic anaemia in his cases with the haemolytic uraemic syndrome.

Finally, during the later stages of her illness, she had several peritoneal dialyses. Sevitt \& Hoffbrand (1969) showed that peritoneal dialyses caused a striking fall in serum folic acid and this was undoubtedly a further significant factor in the development of folic acid deficiency in our patient. One must add that the low serum folic acid level does not prove folate deficiency, as the bacteriological assay may have been upset by the co-trimoxazole, although it is strange that a similar mechanism did not interfere with the estimation of vitamin $\mathbf{B}_{\mathbf{1 2}}$.

\section{Conclusion}

We would suggest that in this situation co-tri- moxazole is administered with small doses of folic acid and that, in fact, the Giovanetti diet itself might be supplemented by a small daily supplement of folic acid.

\section{References}

Allison, M.E.M., Kennedy, A.C., McGeachie, J. \& McDonald, G.A. (1969). Sulphamethoxazole-trimethoprim therapy in urinary tract infection with reference to its haematological effects. Scottish Medical Journal 14, 355.

KAHN, S.B., FeIN, S.A. \& Brodsky, I. (1968) Effects of trimethoprim on folate metabolism in man. Clinical Parmacology and Therapeutics, 9, 550.

Chanarin, I., Dacie, J.V. \& Mollin, D.L. (1959) Folic acid deficiency in haemolytic anaemia. British Journal of Haematology, 5, 245.

Clarkson, A.R., Lawrence, J.R., Meadows, R. \& SEYMOUR, A.E. (1970) The haemolytic syndrome in adults. Quarterly Journal of Medicine, 39, 227.

DeGruchy, G.C. (1970) Clinical Haematology in Medical Practice. 3rd edn, p. 130. Blackwell Scientific Publications, Oxford.

Hulme, B. \& ReEves, D.S. (1971) Leucopenia associated with trimethoprim - sulphamethoxazole after renal transplantation. British Medical Journal, 3, 610 .

SevitT, L.H. \& Hoffbrand, A.V. (1969) Serum folate and vitamin B12 levels in acute and chronic renal disease. Effects of peritoneal dialysis. British Medical Journal, 2, 18.

ShaRPSTONE, P. (1969) The renal handling of trimethoprim and sulphamethoxazole in man. Postgraduate Medical Journal, Suppl. 45, 38.

\title{
Foetus acardius amorphus
}

\author{
Brian Alderman* \\ M.B., CH.B., M.R.C.O.G. \\ Clatterbridge Hospital, Cheshire
}

\section{Summary}

A case of acardius amorphus is reported. The rarity of foetal monsters without a functioning heart is emphasized and the method of classification reviewed. The theories of teratogenesis are discussed. Evidence is presented in support of the theory that there is a primary failure of the organ to develop. The possibility of anoxia and nutritional deficiency of the foetus being solely responsible for the malformation seems unlikely.

\footnotetext{
* Present address: Department of Obstetrics and Gynaecology, University of Liverpool.
}

Gross foetal malformations of the acardiac variety are exceedingly rare. As the name implies, the chief abnormality common to all varieties of the monster is the lack of a functioning heart.

The monster is always one of a pair of uniovular twins, but has been reported in a triplet pregnancy (Ross, 1951). The other foetus, whose heart provides the circulatory force for both twins, is usually normal.

The incidence of acardiac monsters is difficult to ascertain. However, Kappelman (1944) has estimated that they occur approximately once in 34,600 births. 


\section{Classification}

If no trace exists of myocardial elements the monster is referred to as holo-acardius. Should, however, there be any trace of myocardial tissue present, then the term hemi-acardius is applied. As any myocardial tissue present must by definition be rudimentary and non-functioning, this major subdivision seems superfluous.

The many associated malformations fall into no clear-cut categories, but the acardii are for practical purposes divided into sub-groups according to their gross external appearances.

\section{(1) Acardius amorphus}

This variety is the least well developed, bearing no resemblance at all to a human foetus. It usually consists of an ovoid mass with no attempt at head or limb formation.

\section{(2) Acardius myelacephalus}

This resembles the amorphus type except that there is an attempt at rudimentary limb formation.

\section{(3) Acardius acephalus}

This is the commonest variety and is characterized by the lack of a recognizable head. Moderately well developed limbs are usually present.

\section{(4) Acardius anceps (Paracephalus or aceps)}

This is a slightly more developed variety of the acephalus in that a rudimentary head is present.

\section{(5) Acardius acormus}

This is the rarest of the varieties of acardii. It consists of a head without a body. Potter (1961) challenges its existence at all. Certainly references to it in the literature are very scanty.

The least developed or amorphus variety is relatively uncommon even amongst acardii. Out of the 151 cases of acardiac monsters in the world literature reviewed by Napolitani \& Schreiber (1960), only thirty-seven (approximately $25 \%$ ) were acardius amorphus. Because of the excessive rarity of this group the following case of acardius amorphus is reported.

\section{Case report}

A 24-year-old primigravida was admitted to the Clatterbridge Maternity Hospital as an emergency in premature labour at 32 weeks' gestation. Her antenatal progress had been uneventful.

On examination the height of the uterine fundus corresponded with the period of gestation. The foetus presented by the breech and there was no evidence of polyhydramnios.
Soon after admission she had an assisted breech delivery of a living male infant weighing $1532 \mathrm{~g}$. As the placenta failed to separate, a hand was inserted into the uterus with a view to manual removal of the placenta. A soft mass was felt in the uterus which was thought to be a second twin. However, a foetal pole could not be identified and the hand was withdrawn. Spontaneous delivery of a grossly malformed second twin immediately followed. Removal of the placenta was accomplished manually.

Placenta. This was ragged owing to the method of delivery. Its weight was not recorded, but it appeared normal and of a size compatible with a 32 weeks' twin pregnancy. A single chorion was present but it was not possible to be certain of the number of amniotic sacs. A single umbilical cord connected to the normal foetus was centrally inserted. There was no evidence of a second cord.

Both mother and surviving child made an uneventful recovery.

Monster. This was an ovoid object weighing $823 \mathrm{~g}$ (Fig. 1). Dimensions: $18.5 \mathrm{~cm}$ long, $13.5 \mathrm{~cm}$ at its broadest part and $10 \mathrm{~cm}$ thick. It was covered with

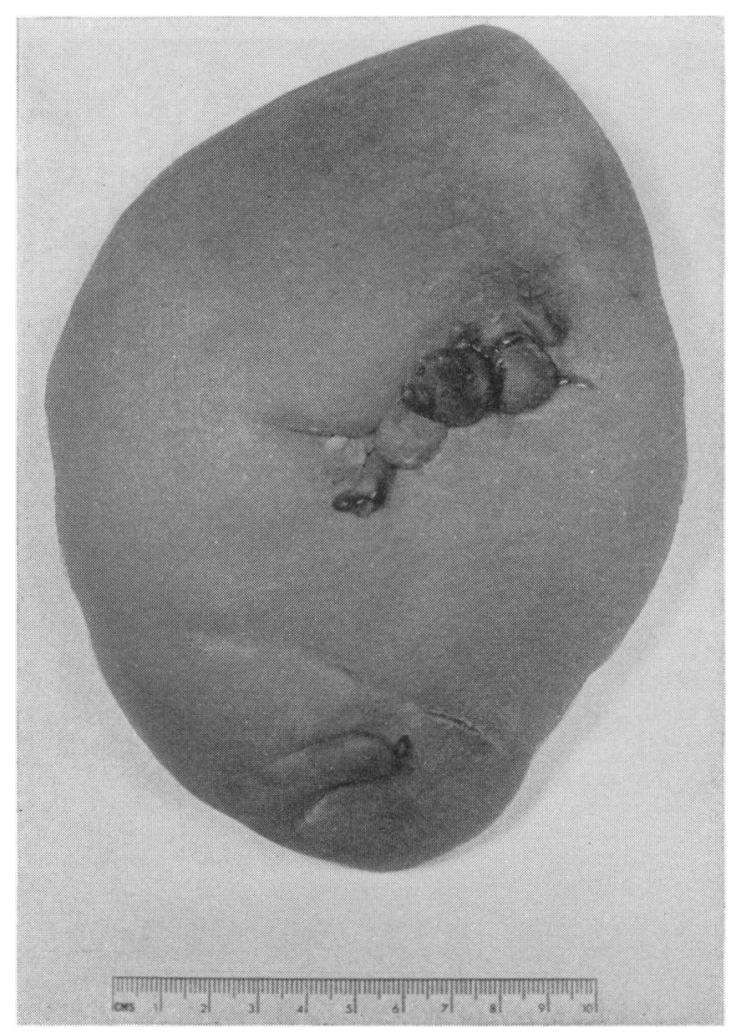

Fig. 1. Ventral surface of foetus amorphus. The stump of umbilical cord is visible at the centre. 
healthy-looking skin, there being no evidence of maceration. The consistency was firm with no obvious oedema. At the centre of what was considered to be the ventral surface, a stump of umbilical cord protruded $1.5 \mathrm{~cm}$ above the surface. This was very slender. Above the cord were three adjacent nodules, each approximately $1 \mathrm{~cm}$ in diameter. At one pole of the monster, in the midline, was a slender projection $2.5 \mathrm{~cm}$ long which presumably represented a hind limb.

$X$-ray (Fig. 2). This revealed a disproportionate amount of soft tissue shadow surrounding a rudimentary vertebral column and rib cage. No heart shadow was present. The vertebral column consisted of only sixteen vertebrae and a large rectangular bone at the caudal end, presumably representing a rudimentary pelvic girdle. Seven ribs were present on each side. The small protuberance at the caudal end of the monster was shown to contain a slim spicule of bone.

Sagittal section (Fig. 3). The specimen was bisected sagitally. At both ends of the monster about a quarter of its length consisted of grey amorphous material which was devoid of any visible blood

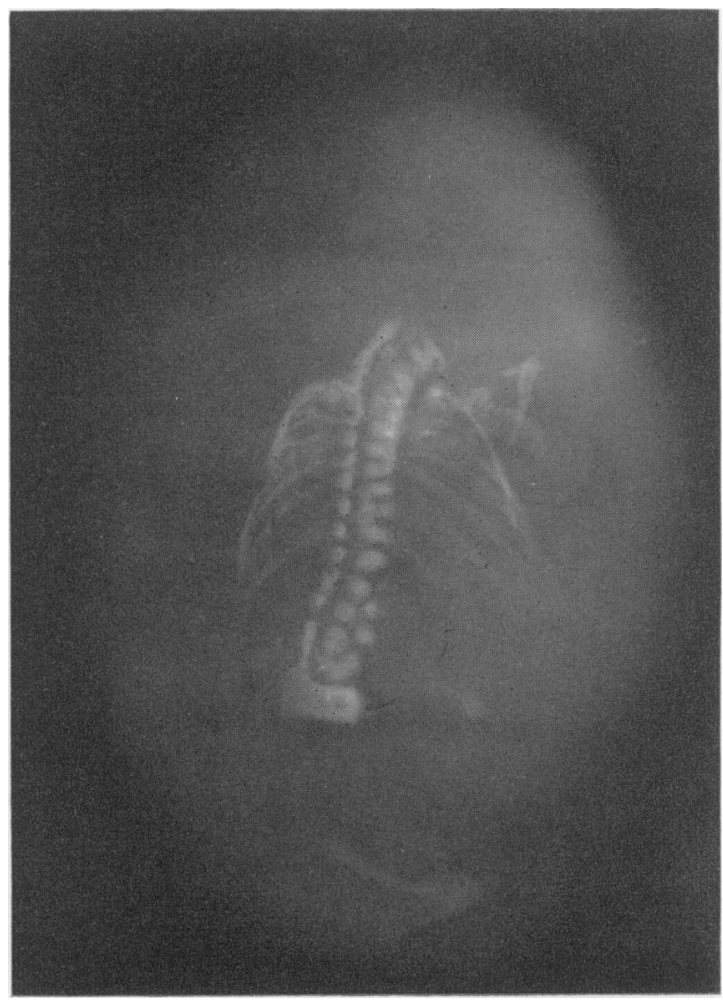

FIG. 2. X-ray of foetus amorphus. Antero-posterior view.

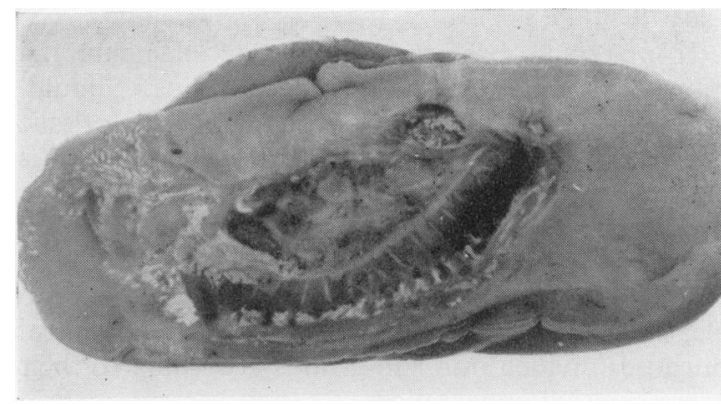

Fig. 3. Sagittal section of foetus amorphus. The umbilical cord originates from the top centre.

vessels. Within the concavity of the vertebral column was a darker area where one would expect to find the abdominal cavity. This contained several small cystic spaces, none of which could be clearly identified as gut. A thoracic cavity could not be identified. The specimen has not been dissected further, but has been preserved in the University of Liverpool Museum.

\section{Diagnosis and management}

The diagnosis is almost invariably made postnatally. The only way in which the diagnosis coulde be made antenatally is by X-ray, and only then by constant alertness for the condition. On the rares occasions that acardiac monsters have been $X$-rayed in utero they have been mistaken for anencephalics (Friedman, 1960).

The normal twin is usually born first, the delivery being uncomplicated. Rare cases of dystocia resulting in abdominal delivery have been reported (Sarma, 1960). There seems to be no increased incidence of associated abnormalities in the accompanying twin, nor is there any report of the malformation having occurred more than once in the same patient.

\section{Aetiology}

There has been a good deal of speculation about the possible pathogenesis of acardiac monsters. The circulation has been well described (Ballantyne, 1904; Campbell \& Shepherd, 1905). Briefly, the umbilical arteries of both twins anastomose on the placental surface or shortly before they reach the placenta. The arterial pressure resulting from the heart action of the normal twin causes a reversal of the direction of blood flow within the umbilical arteries of the weaker twin. Hence perfusion of the monster occurs with blood depleted in oxygen and nutrients.

There are two main theories of aetiology:

(1) The blood pumped from the umbilical artery of the first twin into the second, being deficient in 
oxygen and nutriments causes the recipient twin to become so poorly nourished and anoxic that it develops imperfectly. The monster's heart, being overcome by the reversed flow of blood, then atrophies. This seems to be the most popular theory.

(2) Primary failure of the parts to develop adequately, the chance anastomosis of the two arterial systems merely allowing the potentially blighted ovum to survive during the antenatal period.

It has been suggested by Krause \& Bejdl (1948) that compression of the embryo at the embryonic disc stage may be a factor in its failure to develop.

\section{Discussion}

There are several features which suggest that the popular concept of deficient nutrition being responsible for the malformation may not be an acceptable one.

(1) The healthy appearance of the skin of the specimen reported above was not indicative of anoxia or undernourishment.

(2) One would not expect a foetus which is seriously undernourished to be larger than the foetus which is supposedly getting the greater portion of the nutriments. This often seems to be the case however. Examples are the cases reported by Richart \& Benirschke (1963); Gillim \& Hendricks (1953); and Napolitani \& Schreiber (1960). The monster in Gillim's case was almost two-and-a-half times the size of the normal foetus.

(3) One may expect a heart which has been overcome by the reversed blood flow to become dilated with damaged valves. It may atrophy, but it is unlikely to disappear completely.

(4) Assuming the nutritional theory to be correct, one would expect the organs developing nearest to the source of the de-oxygenated blood to be better developed than those farthest away from it. Thus, the hypogastric arteries conduct the blood initially to the pelvis and lower limbs, the upper extremities being supplied last. This would explain the common occurrence of the acardius acephalus variety of the monster, but it is difficult to apply this theory to the amorphus or acormus types.

If the development of individual organs is examined, it is noted that one organ may be relatively well developed whilst an adjacent organ is very poorly developed or completely missing. For example, in the case reported by Richart \& Benirschke (1963) a spleen, one polycystic kidney and two well developed adrenal glands were present, but no pancreas, liver or stomach were recognized.

(5) Occasionally one organ (usually a long bone) develops normally, complete with epiphyses but in an ectopic situation. Examples are the cases reported by Schwalbe (1906) and Boronow \& West (1964). These are examples of complete self-differentiation in association with rudimentary development of the remainder of the embryo, but are hard to explain in the presence of anoxia and poor nutrition.

Thus, it is difficult to accept that anoxia and depletion of nutriments can be wholly responsible for all the bizarre abnormalities found in acardiac monsters. It seems probable that there has been a primary failure of the parts to develop. Richart \& Benirschke (1963) found forty-six chromosomes to be present in tissue cultures taken from an acardius amorphus. Assuming that the genetic make-up is normal, however, it is possible that one of the monovular twins may be adversely influenced by the environment shortly after division of the zygote. A comparison may be made with the occasional occurrence of anencephaly in one of monozygotic twins, whilst the other twin remains normal.

\section{Acknowledgment}

I am grateful to Mr William Gault, Consultant Obstetrician and Gynaecologist at Clatterbridge Hosptial, Wirral, Cheshire, for encouragement and permission to publish this case.

\section{References}

Ballantyne, J.W. (1904) Manual of Antenatal Pathology and Hygiene. The Embryo, p. 631. Green, Edinburgh.

BoRONOW, R.C. \& WeST, R.H. (1964) Monster acardius parasiticus. American Journal of Obstetrics and Gynaeco$\log y, 88,233$.

CAMPBell, M. \& ShePherd, H.D. (1905) The circulatory and anatomical abnormalities of an acardiac foetus of rare form. Lancet, ii, 941 .

FrIedmaN, H.L. (1960) Holoacardius acephalus. Radiology, 75, 782.

Gillim, D.L. \& HendRICKs, C.H. (1953) Holoacardius: Review of the literature and a case report. Obstetrics and Gynaecology, 2. 647.

Kappelman, M.D. (1944) Acardius amorphus. American Journal of Obstetrics and Gynaecology, 47, 412.

Krause, W. \& BejdL, W. (1948) Quoted by J. R. W. Ross (1951). Journal of Obstetrics and Gynaecology of the British Empire, 58, 845.

NAPOLITANI, F.D. \& SchreIBER, I. (1960) The acardiac monster. American Journal of Obstetrics and Gynaecology, 80, 582.

PotTer, E.L. (1961) Pathology of the Fetus and Infant, 2nd edn. Year Book Publishers, Chicago.

RICHART, R. \& BENIRSCHKE, K. (1963) Holoacardius amorphus. Report of a case with chromosome analysis. American Journal of Obstetrics and Gynaecology, 86, 329.

Ross, J.R.W. (1951) An acardius amorphus in a triplet pregnancy. Journal of Obstetrics and Gynaecology of the British Empire, 58, 845.

SARMA, V. (1960) Holoacardius monster in obstetrics. British Journal of Clinical Practice, 14, 795.

Schwalbe, E. (1906) Quoted by Napolitani and Schreiber (1960). The acardiac monster. American Journal of Obstetrics and Gynaecology, 80, 582. 